\title{
Epidemiological and economic evaluation of foot-and-mouth disease control strategies in the Netherlands
}

\author{
A. A. DIJKHUIZEN \\ Department of Farm Management, Wageningen Agricultural University, P.O. Box 8130, \\ NL $6700 \mathrm{EW}$ Wageningen, Netherlands
}

Received 1 June 1988; accepted 17 October 1988

\begin{abstract}
A Markov chain model on the microcomputer is presented, in which a variety of control strategies with respect to foot-and-mouth disease (FMD) in cattle and pig herds can be examined economically. From an epidemiological point of view, the most favourable results for the Netherlands were obtained under the strategy currently being applied, i.e. annual vaccination of the cattle population in combination with stamping out affected herds and ring vaccination when the disease does occur. From an economic point of view, however, it was found that the annual costs are considerably reduced when ceasing the prophylactic routine vaccination, provided that adequate measures are carried out in case of an outbreak. This conclusion in favour of a non-vaccinated population was hardly influenced by more pessimistic values for the major - uncertain - input factors, and not likely to be outranged by indirect costs due to an increased risk for export bans. More research is underway to model these indirect losses more precisely.
\end{abstract}

Keywords: foot-and-mouth disease, Markov chain, economics, modelling

\section{Introduction}

Foot-and-mouth disease (FMD) is one of the most contagious of animal diseases. It is either endemic (continually present) or sporadic (occasional epidemics), and can affect any cloven-hoofed animal, but cattle and pigs most frequently (Power \& Harris, 1973; Carpenter \& Thieme, 1979).

In the Netherlands the disease is sporadic. For more than 20 years the national cattle herd has been vaccinated annually. During this period the number of outbreaks was reduced significantly: 2300 herds infected in 1966/'67, 28 in 1971/'72, 5 in 1974/'75, 1 in 1977 and 6 in 1983/'84 (FAO, 1986).

The economic feasibility of continued prophylactic vaccination is being discussed. Western European countries like Great Britain, Ireland, Denmark, Norway and Sweden do successfully apply a strategy without routine vaccination. Their 
control is mainly based on 'stamping out', i.e. immediate slaughtering of all susceptible animals in infected herds.

The FAO European Commission for the control of FMD recently discussed prophylactic schemes in Europe and recommended that countries undertake a costbenefit study of alternative control policies before changing strategy. A workinggroup was set up to prepare common criteria for economic analyses which could serve as a guide for the various countries (FAO, 1985).

When applying the proposed approach to Dutch cattle and pig farming a serious lack of empirical data hindered a direct quantification and evaluation of alternative control strategies. Therefore, a user-friendly computer model was created within an electronic spreadsheet program on the microcomputer, making it possible to determine the impact of uncertain input values easily ${ }^{1}$. The model runs with (Dutch) default values, but these can be modified to suit different conditions and countries.

In this paper the structure of the model, the input data and the main results obtained will be discussed.

\section{Model structure and contents}

\section{Epidemiological routine}

To determine the spread of the disease after a primary outbreak, the state-transition approach is used, developed from a Markov chain model. This allows the examination of a variety of control strategies (Miller, 1979). Herds are considered to be in one of four mutually exclusive 'states': susceptible, infectious, immune or removed. Each week, the probability of every transition is calculated and the proportion of herds in each state during the next week is thus derived. Obviously impossible or unimportant pathways are excluded from the analysis, as shown in Table 1.

According to Miller (1979), the probability of a susceptible herd becoming infected $(p i)$ in a particular week $(j)$ is assumed to be a function of the fraction of infectious herds $(f i)$ in the previous week and the dissemination rate $(d r)$ :

$$
p i_{j}=1-e^{-d r_{j-1} \times f i_{j-1}}
$$

The dissemination rate $(d r)$ represents the average number of herds to which agent is delivered by each infected herd. Its value depends upon factors such as herd density, animal movements and type of farming. It decreases in time when outbreaks occur because of increased awareness among farmers, easy targets having been used up, and movement stand-stills, for instance.

The fraction of herds being susceptible, immune or removed depends on the control strategy. The model automatically considers the strategies as given in Table 2 . According to reality, the prophylactic routine vaccination is carried out once a year, and includes all cattle older than 4 months. Pig herds are not included, as their

\footnotetext{
1 The model has been designed in a SuperCalc Spreadsheet, running on an IBM(-compatible) microcomputer with a minimum memory of $256 \mathrm{~K}$, and using the MS-DOS operating system.
} 
Table 1. Pathways ('transitions') considered in the model.

\begin{tabular}{lllll}
\hline From & To & & & \\
\cline { 2 - 5 } & susceptible & infectious & immune & removed \\
Susceptible & $\begin{array}{l}\text { remaining } \\
\text { susceptible }\end{array}$ & infection & $\begin{array}{l}\text { effective } \\
\text { vaccination }\end{array}$ & $\begin{array}{c}\text { 'contact' } \\
\text { slaughter } \\
\text { Infectious }\end{array}$ \\
Immune & -1 & - & - & $\begin{array}{l}\text { 'outbreak' } \\
\text { slaughter }\end{array}$ \\
Removed & - & - & remaining & - \\
& restocking & - & immune & remaining \\
\hline
\end{tabular}

1 - indicates an impossible or unimportant pathway.

Table 2. FMD control strategies considered in the model.

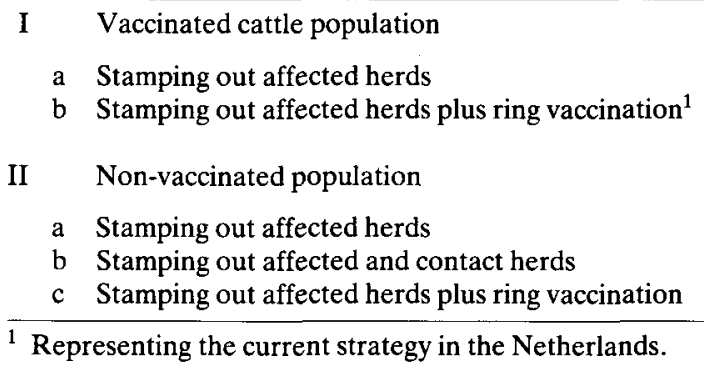

animal flow is too high for reaching a reasonable level of immunity. In case of stamping out, herds with primary outbreaks are assumed to be removed in the model after 10 days. Usually, herds with secondary outbreaks are easier to diagnose because of increased awareness and, therefore, are removed within one week. Restocking takes place after 8 weeks. Ring vaccination, if applied, starts 3 weeks after the primary outbreak(s) and includes all cattle and pigs within a radius of $25 \mathrm{~km}$ around the affected herd(s).

All strategies mentioned in Table 2 are evaluated in the model during a fixed period of 30 weeks. The input factors to be modified are discussed separately (see Section 'Input data').

\section{Economic routine}

FMD control strategies reach beyond the scope of the individual farmer. Decisions on these strategies are taken by the central government, making it obvious to analyse the economic effects at a national level (Renkema \& Dijkhuizen, 1984; McInerney, 1987). Resource prices at this level, however, are usually unknown or difficult 


\section{A. A. DIJKHUIZEN}

Table 3. Cost elements to include in an economic evaluation of FMD control strategies (FAO, 1985).

\begin{tabular}{ll}
\hline Routine vaccination & Stamping out \\
$\begin{array}{l}\text { Vaccination program } \\
\begin{array}{l}\text { Vaccine (including emergency } \\
\text { vaccine bank) and storage } \\
\text { Vaccination }\end{array} \\
\text { Side effects }\end{array}$ & $\begin{array}{l}\text { Maintaining a vaccine bank } \\
\text { Vaccine and storage }\end{array}$ \\
FMD outbreak & \\
$\begin{array}{l}\text { Controlling outbreaks } \\
\text { including ring vaccination } \\
\text { (if carried out) }\end{array}$ & FMD outbreak \\
$\begin{array}{l}\text { Slaughtered animals } \\
\text { Loss of production } \\
\text { Interruption of domestic trade }\end{array}$ & $\begin{array}{c}\text { Controlling outbreaks } \\
\text { including ring vaccination } \\
\text { (if carried out) }\end{array}$ \\
$\begin{array}{l}\text { Loss of export trade } \\
\text { Effect of national } \\
\text { vaccination status }\end{array}$ & $\begin{array}{l}\text { Slaughtered animals } \\
\text { Interruption of domestic trade }\end{array}$ \\
& $\begin{array}{l}\text { Loss of export trade } \\
\text { Effect of change in national } \\
\text { vaccination status if ring }\end{array}$ \\
\hline
\end{tabular}

to establish. For this reason, normal market prices are used in the analyses, though adjusted for any internal transfer payments (i.e. subsidies and sales taxes).

The economic guidelines provided by the FAO (FAO, 1985) have served as a basis for the cost elements to be included in the model. These elements are summarized in Table 3. No algorithm is available yet to model the - indirect - losses of export bans. Size and duration of such bans are usually dependent on political decisions as well, making it very arbitrary to quantitatively predict the losses within each of the control strategies. In the model, therefore, only the direct losses of outbreaks are considered. Hence, expected differences in risk for export bans have to be included - subjectively - in the final stage of the decision-making process.

\section{Input data}

As a logical result of the sporadic form of FMD in most European countries, there are very few empirical data available to serve as a base for the economic analysis. The most recent and comprehensive information even dates back to about 20 years ago, and concerns Great Britain (Miller, 1979). Then, the Netherlands also suffered from a large FMD outbreak, but no appropriate data were obtained for further analysis.

Because of this serious lack of published information, a working-group was installed to provide the necessary set of input data. The current default values thus represent the common opinion of Dutch FMD-experts (Dijkhuizen et al., 1986). In addition, the computer model has been made flexible regarding input modification, making it easier to determine the impact of uncertain values. 
Table 4. Default values of the epidemiological input data.

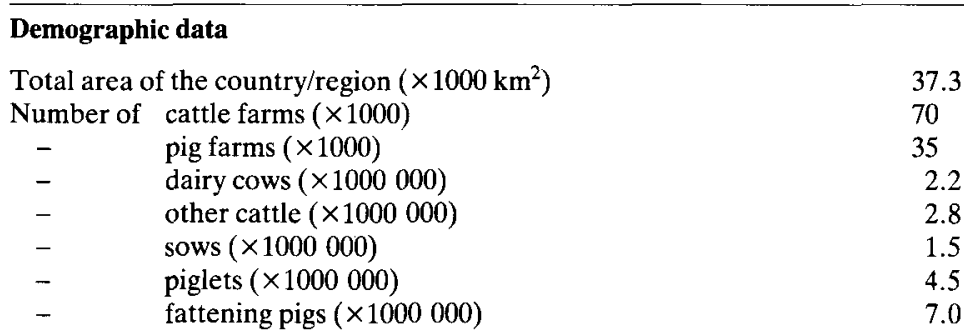

Expected number of primary outbreaks per 10 years

Vaccinated cattle population

- most favourable situation

- most likely situation

- most unfavourable situation

Non-vaccinated population

- most favourable situation

- most likely situation

- most unfavourable situation

Number of herds involved in a primary outbreak (week 1)

Cattle farms

Pig farms

Dissemination rate for herds being infected in:

week 1

week 2

week 3

week 4

week 5

week 6 and further

\section{Additional data control strategies}

Routine vaccination

$\%$ of cattle involved

$\%$ of pigs involved

Ring vaccination (in week 3)

$\%$ of herds outside the ring protected

- from up week 5

- from up week 6 (in case of an effective vaccination)

- from up week 6 (in case of a non-effective vaccination)

Stamping out contact herds

Risky contacts per affected herd

- in week 1

- in week 2

- from up week 3

$\%$ of potential outbreaks prevented 


\section{A. A. DIJKHUIZEN}

With respect to the epidemiological routine, about 30 input variables can be modified. Their default values are summarized in Table 4 . The most difficult factor to predict is the probability of primary outbreaks. Hence, the model considers a most favourable, a most likely, and a most unfavourable prediction for both a vaccinated and a non-vaccinated population. The relatively higher number of primary outbreaks to be expected for the most likely situation in case of routine vaccination is due to the risk generated by the presence of vaccine or vaccine plants (Strohmaier \& Böhm, 1984).

Table 5. Default values of the economic input data.

\section{Cost elements of vaccination}

Vaccine costs cattle per dose (Dfl.)

Vaccination costs per animal, including vaccine (Dfl.)

- first 50 cattle on the farm

- other cattle on the farm

- first 50 pigs on the farm

- other pigs on the farm

\section{Cost elements of stamping out}

Costs per average cattle farm (Dfl. $\times 1000)$

- removed animals

- others (taxation, transport, desinfection, etc.)

Costs per average pig farm $(\mathrm{Dfl} . \times 1000)$

- removed animals

- others (taxation, transport, disinfection, etc.)

Costs idle production factors

- cattle farms (Dfl./cow/day)

- swine breeding farms (Dfl./sow/day)

- pig fattening farms (Dfl./hog/day)

Incidentals on cattle and pig farms

$\%$ of losses removed animals

Missed net cash flow industry and trade

- per average removed cow (Dfl.)

- per average removed pig (Dfl.)

Annual discount factor $(\%)$

\section{Miscellaneous}

EC-subsidy for ring vaccination

$-\%$ of vaccine costs

- \% of vaccination costs

EC-subsidy for stamping out

- non-vaccinated population: $\%$ of costs repayed

- vaccinated population: all costs repaid up to the minimum of either: number of outbreaks 
The default values in the economic routine are presented in Table 5. Most of them could be based on existing financial arrangements, except for the costs caused by a delay in restocking of removed herds. For that, the cost of idle production factors on farms was calculated as the average margin between gross returns and variable costs per day of delay (Dijkhuizen, 1989). For industrial firms, an estimate was made for the missed net cash flow per average removed cow or pig, respectively.

\section{Results}

\section{Basic situation}

The highest number of secundary outbreaks occur, as could be expected, in a nonvaccinated population with stamping out of the affected herds as the only control strategy (Table 6). Then, as shown in Figure 1, weekly outbreaks increase in number during the first 6 weeks, despite a declining dissemination rate. In total, the outbreaks even persist for over 6 months.

Routine prophylactic vaccination is not necessarily the only remedy against such a dramatic spread of the disease, as shown in Table 6 . The total number of outbreaks and the length of time in which they occur can also considerably been reduced by stamping out the risky contact herds as well. It is doubtful, however, if public opinion does allow slaughtering animals of so many herds without clinical signs of the disease. On the other hand, the total number of removed herds hardly

Table 6. Summary of the epidemiological results in case of an outbreak.

\begin{tabular}{llll}
\hline Control strategy & $\begin{array}{l}\text { Number of } \\
\text { weeks with } \\
\text { outbreaks }\end{array}$ & $\begin{array}{l}\text { Number of } \\
\text { outbreaks }\end{array}$ & $\begin{array}{l}\text { Number of herds } \\
\text { removed }^{1}\end{array}$
\end{tabular}

I Vaccinated cattle population

a Stamping out affected herds

b1 Stamping out affected herds, plus effective ring vaccination

b2 Stamping out affected herds, plus non-effective ring vaccination

$\begin{array}{rrr}7 & 21 & 21 \\ 5 & 16 & 16 \\ 5 & 17 & 17 \\ & & \\ 29 & 712 & 712 \\ 8 & 59 & 140 \\ 5 & 134 & 134 \\ 8 & 170 & 170\end{array}$

${ }^{1}$ Cattle and pig farms assumed to be included according to their ratio in the initial susceptible population. 


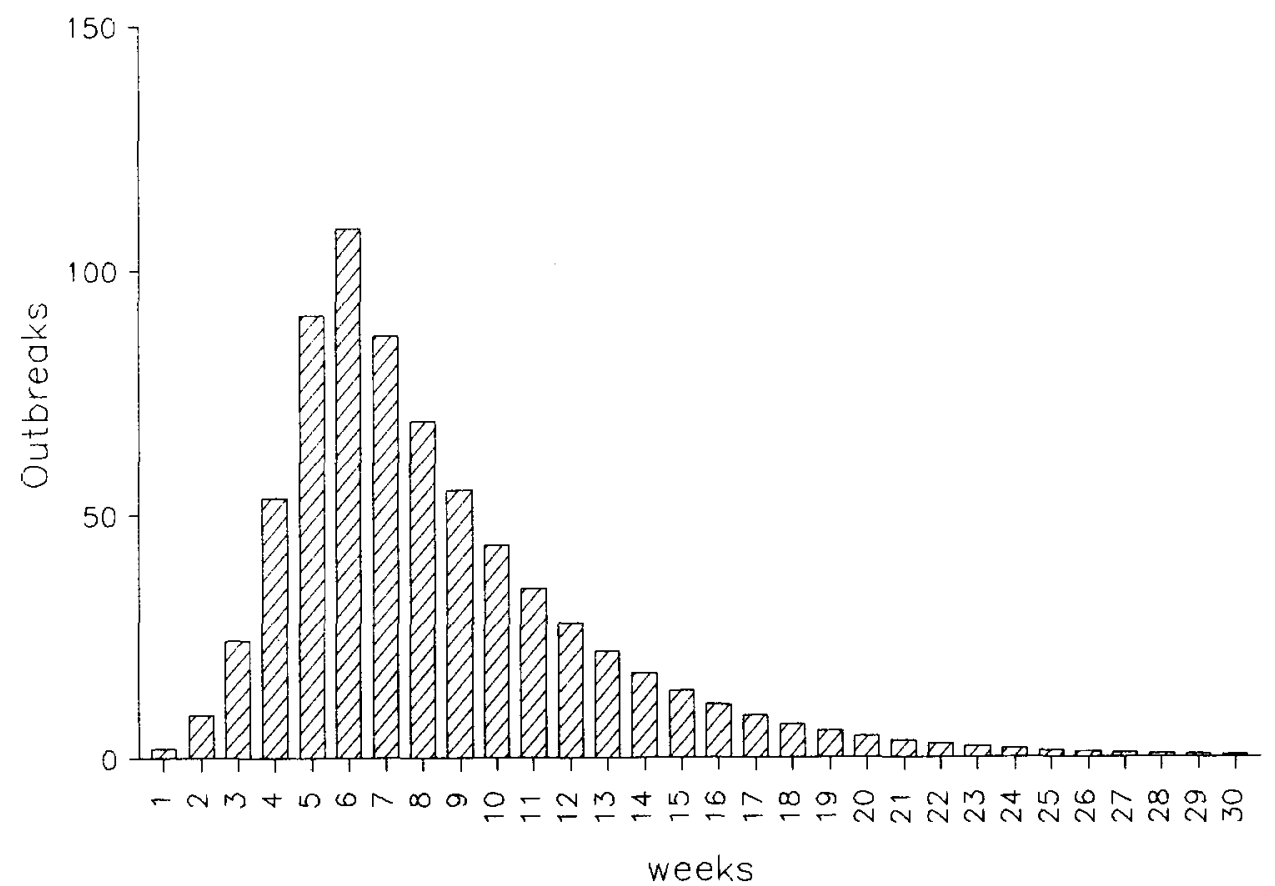

Fig. 1. Number of secondary outbreaks in a non-vaccinated population, with stamping out affected herds as the only control strategy.

exceeds that in case of the strategy in which stamping out of the affected herds is combined with a ring vaccination, even when a break-through occurs (non-effective ring vaccination).

The number of secundary outbreaks is by far the most reduced when the cattle population is vaccinated routinely. The most favourable-epidemiological-results are obtained then under the strategy currently being applied in the Netherlands (i.e. stamping out affected herds in combination with ring vaccination if outbreaks do occur). But even with a strategy of stamping out affected herds only, or when a break-through occurs in case of ring vaccination, the total number of outbreaks remains limited.

Given these predicted numbers of secundary outbreaks, the calculated direct losses under each of the strategies are summarized in Table 7. The major loss item turns out to be the cost of slaughtered animals. Hence, the extent of the total losses is closely related to the number of removed herds. Taking into account the current EC-subsidies (Table 5), total calculated losses are the lowest under the strategy of stamping out affected herds plus an effective ring vaccination, both in a vaccinated and in a non-vaccinated population. The cost of a routine vaccination of the cattle population is calculated as slightly more than 24 million Dutch guilders (Dfl.), shown in Table 7 . No extra costs were charged for maintaining a strategic store of vaccine, assuming no significant differences between the strategies considered. 
Table 7. Total direct economic losses in case of an outbreak (Dfl. $\times 1000)$.

\begin{tabular}{|c|c|c|c|c|c|c|c|}
\hline \multirow[b]{3}{*}{ Routine vaccination } & \multicolumn{3}{|c|}{ Vaccinated cattle population } & \multicolumn{4}{|c|}{ Non-vaccinated population } \\
\hline & $\overline{\mathrm{Ia}^{1}}$ & $\mathrm{Ib} 1$ & $\mathrm{Ib} 2$ & $\overline{\text { IIa }}$ & $\mathrm{IIb}$ & IIc1 & IIc2 \\
\hline & 24076 & 24076 & 24076 & 0 & 0 & 0 & 0 \\
\hline \multicolumn{8}{|l|}{ FMD-outbreaks } \\
\hline $\begin{array}{l}\text { Controlling outbreaks } \\
\text { - desinf. }+ \text { incidentals }\end{array}$ & 560 & 448 & 461 & 19389 & 3820 & 3657 & 4619 \\
\hline - ring vaccination & 0 & 3587 & 7172 & 0 & 0 & 3587 & 7172 \\
\hline - admin. + diagn. support & $--^{2}$ & - & - & - & - & - & - \\
\hline \multicolumn{8}{|l|}{ Slaughtered animals } \\
\hline - farms & 2198 & 1756 & 1809 & 76135 & 14997 & 14357 & 18136 \\
\hline - industry and trade & 2564 & 2047 & 2108 & 89780 & 17682 & 16931 & 21384 \\
\hline \multicolumn{8}{|l|}{ Lost production } \\
\hline- farms & 229 & 183 & 188 & 7916 & 1559 & 1493 & 1886 \\
\hline - industry and trade & 382 & 304 & 316 & 12278 & 2422 & 2312 & 2928 \\
\hline Interrupt. domestic trade & - & - & - & - & - & - & - \\
\hline Total direct losses & 5933 & 8325 & 12054 & 205498 & 40480 & 42337 & 56125 \\
\hline Total minus EC-subsidy & 4104 & 3690 & 4614 & 161543 & 31821 & 31242 & 40042 \\
\hline
\end{tabular}

1 See Table 6.

${ }^{2}$ As yet unquantified.

Table 8 . Summary of the direct costs on a yearly base (Dfl. $\times 1000)$.

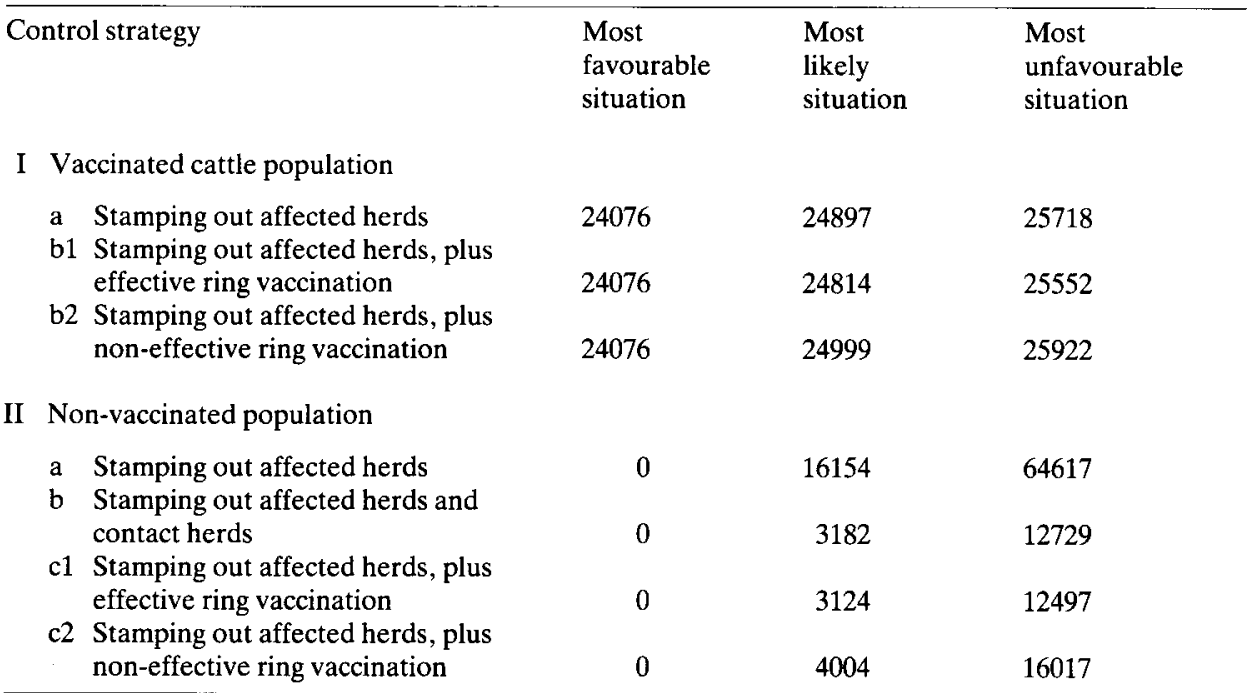




\section{A. A. DIJKHUIZEN}

The final comparison of the total direct costs should be done on a yearly base, taking into account the expected frequency of primary outbreaks. In case of the most favourable situation regarding the number of primary outbreaks $(0$ within 10 years), routine vaccination of the cattle population, of course, is far from profitable as shown in Table 8. But also in the most likely situation, the annual costs are the lowest in a non-vaccinated population, even with stamping out of the affected herds as the only strategy. It is under the latter strategy that the costs are rising by far the highest in case of the most unfavourable situation considering the expected number of primary outbreaks. The other strategies, however, still provide the best economic results in case of a non-vaccinated population. Even when comparing the direct costs in the most favourable situation for a vaccinated cattle population on the one hand and in the most unfavourable situation for a non-vaccinated population on the other, routine vaccination is still the less profitable choice.

\section{Sensitivity analysis}

Taking into account the most likely situation with respect to the number of primary outbreaks, more pessimistic values for the major uncertain input factors hardly influence the previous favouring conclusions for a non-vaccinated population, as shown in Table 9. Reduced effectiveness from stamping out risky contact herds and ring vaccination, as well as a ceasing of the EC-subsidies do increase the annual costs, but not tremendously. Even in case of a significantly increased dissemination rate it is possible to keep the direct costs far below the level as calculated before in a vaccinated cattle population (Table 8), at least if adequate control measures are carried out. Should stamping out affected herds then be the only strategy (IIa), the costs do get out of control, as shown in Table 9.

Table 9. Results sensitivity analysis for 'the most likely situation' in a non-vaccinated cattle population (annual losses in Dfl. $\times 1000$ ).

\begin{tabular}{|c|c|c|c|c|}
\hline & \multicolumn{4}{|c|}{ Control strategies (see Table 4) } \\
\hline & IIa & IIb & IIc1 & IIc2 \\
\hline Basic situation (see Table 8) & 16154 & 3182 & 3124 & 4004 \\
\hline \multicolumn{5}{|l|}{ Changed factors ${ }^{1}$ : } \\
\hline Increased dissemination rate ${ }^{2}$ & 2035493 & 9404 & 5876 & 11040 \\
\hline $\begin{array}{l}\% \text { of potential outbreaks prevented } \\
\text { with stamping out contact herds: } 25\end{array}$ & 16154 & 8797 & 3124 & 4004 \\
\hline $\begin{array}{l}\% \text { of herds protected from up week } \\
6 \text { in a non-effective ring vaccination: } 50\end{array}$ & 16154 & 3182 & 3124 & 7234 \\
\hline No EC-subsidies at all & 20550 & 4048 & 4234 & 5612 \\
\hline
\end{tabular}

${ }_{1}^{1}$ Only one factor is changed at a time.

${ }^{2}$ For week 1 through 6 and further: $4.5,3.5,3.0,2.5,2.0,1.5$, respectively. 


\section{Discussion}

To document the profitability of alternative control strategies for highly contagious diseases such as foot-and-mouth disease (FMD), it is not feasible to provide experiments under field conditions. Simulation modelling has long been recognized as a comprehensive technique for this kind of evaluation (Hesselbach \& Eisgruber, 1967). Although it does not solve the existing problem of a lack of empirical data, the significance of gaps in veterinary knowledge can be quantified in this way. Once available, such models can also play a continuing role in supporting real-life decisions, especially when extended with flexible input features and applied to microcomputers, as demonstrated in this paper. That also creates the possibility for simulating other countries with one and the same model, providing optimal conditions for the comparability of the results.

Calculations showed that the current routine vaccination of the cattle population does not seem to be the most profitable strategy for the Netherlands. Annual direct costs are expected to decrease considerably when ceasing the prophylactic vaccination, although adequate measures have to be taken when the disease does occur. This favouring conclusion for a non-vaccinated population was hardly influenced by more pessimistic values for the major uncertain input factors.

Not yet included in the analysis, however, are the indirect losses of potential export bans. Taking into consideration the most adequate strategies only (Table 7), it is in fact a matter of weighing the risk in this respect of the higher number of secundary outbreaks to be expected in a non-vaccinated population (Table 6) against the higher frequency of primary outbreaks as supposed to occur in a vaccinated cattle population (Table 4). Although extremely important in itself, especially for Dutch agriculture (LEI, 1987), such a difference in risk of export bans is unlikely to outrange entirely the highly favouring position of adequate strategies in a non-vaccinated population (Table 7). The more so, when taking into account the consumers' benefits of a fall in prices due to a temporary oversupply in the domestic market, which can compensate to a large extent the producers' loss in income. But, national governments do have the competence, of course, to give special priority to certain interests within their society, e.g. the producers' income. More research, therefore, is underway to model the extent of these indirect losses more precisely.

\section{Acknowledgements}

The author is indebted to J. A. Smak and P. C. van der Valk (Veterinary Services, The Hague) and C. Terpstra (Central Veterinary Institute, Lelystad) for providing the veterinary framework and input values of the FMD-model.

\section{References}

Carpenter, T. E. \& A. Thieme, 1979. A simulation approach to measuring the economic effects of footand-mouth disease in beef and dairy cattle. Proceedings 2nd Symposium on Veterinary Epidemiology and Economics (Canberra), p. 511-516. 


\section{A. A. DIJKHUIZEN}

Dijkhuizen, A. A., 1989. Economic aspects of common health and fertility problems for the individual pig producer: a review. The Veterinary Quarterly (accepted for publication).

Dijkhuizen, A. A., J. A. Smak, P. C. van der Valk \& C. Terpstra, 1986. Input factors of the FMD spreadsheet model. Research report Dutch FMD-Working Group, Department of Farm Management, Wageningen Agricultural University, Wageningen, $14 \mathrm{pp}$.

FAO/European Commission for the control of foot-and-mouth disease, 1985. A guide to an economic evaluation of FMD vaccination programmes. 26th Session of the European Commission, Rome, 13 pp.

FAO/European Commission for the control of foot-and-mouth disease, 1986. Documents and statistics on FMD. Proceedings FMD Symposium, Pirbright (England), p. 1-11.

Hesselbach, J. \& L. M. Eisgruber, 1967. Betriebliche Entscheidungen mittels Simulation. Verlag Paul Parey, Hamburg, 412 pp.

LEI, 1987. Agricultural data 1987 (in Dutch). ISSN 0168-4019, LEI, The Hague.

McInerney, J.P., 1987. An economist's approach to estimate disease losses. Proceedings CEC-Seminar on 'Disease in farm livestock: Economics and policy' (Exeter), p. 35-59.

Miller, W. M., 1979. A state-transition model of epidemic foot-and-mouth disease. McCauley et al., Minnesota, p. 56-72.

Power, A. P. \& S. A. Harris, 1973. A cost/benefit evaluation of alternative control policies for foot-andmouth disease in Great Britain. Proceedings Agricultural Economics Society, England, p. 1-31.

Renkema, J. A. \& A. A. Dijkhuizen, 1984. Economic aspects of diseases in animals, with special reference to the evaluation of preventive health programs. Proceedings 4th Congress of the European Association of Agricultural Economists (Kiel), p. 80-90.

Strohmaier, K. \& H. O. Böhm, 1984. Die Maul- und Klauenseuche II. Epidemiologische Analyse der Ausbrüche seit Einführung des Flächenimpfung in der Bundesrepublik Deutschland. Tierärzliche Umschau 39: 949-961. 